\title{
Incidence, Characteristics and Atherosclerotic Involvement of Coronary Artery Anomalies in Adult Population Undergoing Catheter Coronary Angiography
}

\author{
Navdeep Singh Sidhu ${ }^{\mathrm{a}, \mathrm{d}}$, Gagandeep Singh Wander ${ }^{\mathrm{b}}$, \\ Anmol Monga ${ }^{\mathrm{c}}$, Arashdeep Kaur ${ }^{\mathrm{c}}$
}

\begin{abstract}
Background: Coronary artery anomalies (CAAs) are rare disorders of coronary anatomy with varied clinical presentations. There are widespread geographic variations in incidence and patterns of these anomalies, with limited data from North Indian population. We performed a retrospective study to evaluate the incidence, characteristics and atherosclerotic involvement of CAAs in adult population undergoing catheter coronary angiography.
\end{abstract}

Methods: Serial coronary angiographies performed at our institution over a period of 2.5 years (from January 2017 to June 2019) were retrospectively analyzed. We identified patients with anomalous coronaries and studied their clinical characteristics and angiographic profiles.

Results: Among 3,233 coronary angiograms analyzed, CAAs were found in 99 patients with an incidence of $3.06 \%$. Mean age of the patients was $56.2 \pm 12.9$ years (range: 20 - 86 years), with $74.75 \%$ being males and $25.25 \%$ females. Split right coronary artery (RCA) was the most common coronary anomaly, being seen in 27 patients; with an angiographic incidence of $0.84 \%$. Dual left anterior descending artery (LAD) was the second most common anomaly and was seen in 22 cases with an angiographic incidence of $0.68 \%$. Absent left main trunk was noted in 14 patients $(0.43 \%)$. Ectopic origin of RCA from left sinus was seen in 12 patients $(0.37 \%)$, while ectopic origin of RCA from ascending aorta was seen in four patients $(0.12 \%)$. Ectopic origin of left circumflex artery (LCX) from right sinus or RCA was noted in 13 patients $(0.40 \%)$. One patient $(0.03 \%)$ had a superdominant LAD supplying the posterior descending artery (PDA). Coronary

Manuscript submitted September 1, 2019, accepted October 3, 2019

aDepartment of Cardiology, GGS Medical College and Hospital, Faridkot, Punjab, India

${ }^{b}$ Department of Cardiology, Medanta-the-Medicity, Gurugram, Haryana, India (formerly at Department of Cardiology, GGS Medical College and Hospital, Faridkot, Punjab, India)

'Department of Medicine, GGS Medical College and Hospital, Faridkot, Punjab, India

${ }^{\mathrm{d} C}$ Corresponding Author: Navdeep Singh Sidhu, Department of Cardiology, GGS Medical College and Hospital, Faridkot, Punjab, India.

Email: navsids@gmail.com

doi: https://doi.org/10.14740/cr941 artery fistulae were seen in six patients $(0.18 \%)$. Significant coronary artery disease (CAD) was seen in 89 of 268 (33.21\%) normal vessels, whereas it was seen in 56 of $114(49.12 \%)$ of anomalous vessels. This difference was statistically significant $(\mathrm{P}=0.003)$.

Conclusions: The incidence of CAAs in our study was slightly higher than many of the previous angiographic series. The patterns of coronary anomalies in our study were different from most of the previous studies. Our study had higher incidence of atherosclerotic involvement of anomalous vessels as compared to normal vessels.

Keywords: Coronary artery anomalies; Atherosclerosis; Coronary artery disease; Left anterior descending artery; Left circumflex artery; Right coronary artery; Left main trunk; Split right coronary artery; Dual left anterior descending artery

\section{Introduction}

Coronary artery anomalies (CAAs) are a relatively uncommon, diverse group of congenital disorders of coronary arterial anatomy with a wide variety of clinical presentations. Though most commonly detected incidentally during coronary angiography or at autopsy, these anomalies have generated considerable interest as they constitute the second most common cause of sudden cardiac death in young competitive athletes after hypertrophic cardiomyopathy [1]. Although benign in majority of cases, about one-fifth of coronary anomalies may lead to life-threatening manifestations such as arrhythmias, syncope, sudden death or myocardial infarction [2,3].

Presence of a coronary anomaly should be suspected in a young individual who experiences exertional syncope, exercise induced arrhythmias, myocardial infarction, or cardiac arrest.

Incidence of CAAs has been reported to be $0.6 \%$ to $5.64 \%$ in angiographic series and $0.3 \%$ in autopsy series [2-13]. In the absence of a unifying scientific statement/guidelines from any of major cardiovascular societies regarding definition, nomenclature and classification system of coronary anomalies, many such nomenclatures and classifications have been proposed from time to time [14-20]. Nomenclature and classification pattern proposed by Angelini and coworkers has been the most widely accepted system of classification $[10,19,21$, 
22]. They proposed the following definition of coronary artery patterns: 1) Normal: any morphological pattern seen in $>1 \%$ of an unselected general population; 2) Normal variant: an alternative, relatively uncommon morphological pattern seen in $>1 \%$ of the same population; 3) Anomaly: a morphological pattern seen in $<1 \%$ of the same population.

Atherosclerotic involvement of anomalous coronaries as compared to normal coronaries is also a subject of active research with few studies showing increased susceptibility of anomalous coronaries to atherosclerosis as compared to normal coronaries [23, 24].

Performing coronary angiography in patients with CAAs can be challenging with increased fluoroscopic times. The operator should be able to accurately identify the anomaly and perform adequate evaluation in order to avoid errors in management of the patient. The cardiac surgeon must be aware of the anomalous anatomy so that inadvertent injuries like ligation or transection can be avoided during surgery.

There are widespread geographic variations in incidence and patterns of CAAs. There are limited data on CAAs from India especially on Punjabi population of North India. This study was planned to estimate the incidence, patterns and atherosclerotic involvement of anomalous coronaries in patients undergoing invasive coronary angiography at our tertiary care institution.

\section{Materials and Methods}

This retrospective descriptive study was conducted at the Department of Cardiology, GGS Medical College and Hospital, Faridkot, Punjab, India. Ours is a tertiary care referral institute with fully equipped cardiac catheterization laboratory. The study protocol was approved by our Institutional Review Board, and the study was conducted in accordance with the Declaration of Helsinki. A total of 3,233 coronary angiograms performed at our institution during a period of 2.5 years (from January 2017 to June 2019) were reviewed independently by two experienced invasive cardiologists for the presence of CAAs according to following criteria.

\section{Inclusion criteria}

Adult patients more than 18 years of age who underwent coronary angiography (CAG) for various indications like ischemic heart disease (IHD), left ventricular (LV) dysfunction or valvular heart disease etc. were included in this study.

\section{Exclusion criteria}

1) Patients with congenital heart diseases were excluded from the study population; 2) Patients with separate origin of the conus branch from the right coronary sinus (RCS); 3) Patients with origin of right ventricular branch from the RCS; 4) $\mathrm{Pa}$ tients with other coronary anomalies like coronary ectasia, myocardial bridging, and abnormal high and low origin of coronary arteries from normal sinus.

In case of any difference of opinion between the two reviewers, a consensus was reached after mutual discussion. The course of anomalous artery was determined according to methods described by Yamanaka and Hobbs and the "dot and eye" method [2, 25]. The coronary anomalies were classified primarily based on classification system proposed by Angelini and coworkers (Table 1 [22]).

Significant coronary artery disease (CAD) was diagnosed when $>50 \%$ diameter stenosis was seen in one or more vessels or in a major branch [26]. Atherosclerotic involvement of anomalous coronary arteries was compared with normal coronary arteries of the same patients, which served as the control group. In cases with absent left main trunk, both left anterior descending artery (LAD) and left circumflex artery (LCX) were considered to be anomalous vessels. The hospital records of all patients with coronary anomalies were retrieved from the institutional database. These records were analyzed to study demographic factors, cardiovascular risk factors and clinical presentation.

\section{Statistical analysis}

Statistical analysis was done by using SPSS software Version 22.0 (SPSS Inc., Chicago, IL, USA). Data were presented as mean, standard deviation and as percentages. Chi-square test was used to compare the presence of significant CAD in anomalous and normal coronary arteries. A P value $<0.05$ was considered as statistically significant.

\section{Results}

Out of 3,233 coronary angiograms analyzed, CAAs were found in 99 patients with an incidence of $3.06 \%$.

\section{Clinical characteristics of the patients}

Mean age of the patients was $56.2 \pm 12.9$ years (range: 20 86 years). Seventy-four patients $(74.75 \%)$ were males and 25 patients $(25.25 \%)$ were females. Indication for CAG was acute coronary syndromes in $43(43.43 \%)$ patients, stable IHD with exertion angina or dyspnea on exertion in $25(25.25 \%)$ patients, atypical chest pain with electrocardiographic (ECG) or echocardiographic changes in $22(22.22 \%)$ patients, heart failure or LV dysfunction in seven $(7.07 \%)$ patients and workup prior to permanent pacemaker implantation (due to concomitant chest pain or dyspnea) in two (2.02\%) patients. Considering the coronary risk factors, hypertension was present in $41(41.41 \%)$ patients, diabetes mellitus in $33(33.33 \%)$ patients, dyslipidemia in $19(19.19 \%)$ patients and smoking in $26(26.26 \%)$ patients (Table 2$)$.

\section{Incidence and patterns of coronary anomalies}

Out of 3,233 coronary angiograms analyzed, coronary anoma- 


\section{Table 1. Angelini Classification System for Coronary Anomalies}

Anomalies of origin and course

Absent left main trunk

Anomalous location of coronary ostium within aortic root or adjacent to proper aortic sinus

Anomalous location of coronary ostium outside normal coronary sinuses

Anomalous location of coronary ostium at improper sinus

Single coronary artery

Anomalies of intrinsic coronary arterial anatomy

Congenital ostial stenosis or atresia

Coronary ostial dimple

Coronary ectasia or aneurysm

Absent coronary artery

Coronary hypoplasia

Intramural coronary artery (myocardial bridging)

Subendocardial coronary course

Coronary crossing

Anomalous origin of posterior descending artery from LAD or from a septal branch

Split RCA

Split LAD/dual LAD

Ectopic origination of first septal branch

Anomalies of coronary termination

Inadequate arteriolar/capillary ramifications

Fistulas from RCA, LCA, or conus artery

Anomalous anastomotic vessels

LAD: left anterior descending artery; RCA: right coronary artery; LCA: left coronary artery.

Table 2. Clinical Characteristics of 99 Patients With Coronary Anomalies

\begin{tabular}{ll}
\hline Clinical characteristics & N (\%) \\
\hline Gender & $74(74.75 \%)$ \\
\hline Male & $25(25.25 \%)$ \\
Female & $43(43.43 \%)$ \\
Indication for coronary angiography & $25(25.25 \%)$ \\
Acute coronary syndromes & $22(22.22 \%)$ \\
Stable ischemic heart disease (angina/dyspnea on exertion) & $7(7.07 \%)$ \\
Atypical chest pain with Electrocardiographic/ Echocardiographic changes & $2(2.02 \%)$ \\
Heart failure or LV dysfunction & $41(41.41 \%)$ \\
Workup prior to pacemaker implantation & $33(33.33 \%)$ \\
Risk factors & $19(19.19 \%)$ \\
Hypertension & $26(26.26 \%)$ \\
Diabetes mellitus & \\
Dyslipidemia & \\
Smoking & \\
\hline
\end{tabular}

LV: left ventricle. 
Table 3. Incidence and Patterns of Coronary Anomalies in Our Study

\begin{tabular}{|c|c|c|c|}
\hline Anomaly & $\mathbf{N}$ & Incidence (\%) & Anomaly (\%) \\
\hline Total coronary angiographies & 3,233 & & \\
\hline Total coronary anomalies & 99 & 3.06 & \\
\hline \multicolumn{4}{|l|}{ Anomalies of origin and distribution } \\
\hline Absent left main trunk ${ }^{\mathrm{a}}$ & 14 & 0.43 & 14.14 \\
\hline RCA from left sinus ${ }^{b}$ & 12 & 0.37 & 12.12 \\
\hline $\mathrm{LCX}$ from right sinus/RCA ${ }^{\mathrm{a}}$ & 13 & 0.40 & 13.13 \\
\hline \multicolumn{4}{|l|}{ Anomalies of intrinsic coronary arterial anatomy } \\
\hline Split RCA ${ }^{\mathrm{a}}$ & 27 & 0.84 & 27.27 \\
\hline Dual LAD ${ }^{\mathrm{a}}$ & 22 & 0.68 & 22.22 \\
\hline
\end{tabular}

aUsually benign. ${ }^{b}$ Potentially serious. ' Small fistulae are usually benign, large or multiple fistulae can lead to serious manifestations. LAD: left anterior descending artery; RCA: right coronary artery; LCX: left circumflex artery; PDA: posterior descending artery.

lies were seen in $99(3.06 \%)$ patients (Table 3). These anomalies were classified as per Angelini classification (Table 1 [22]).

\section{Anomalies of origin and distribution}

Absent left main trunk (Fig. 1) was seen in 14 patients, with angiographic incidence of $0.43 \%$ and anomaly incidence of

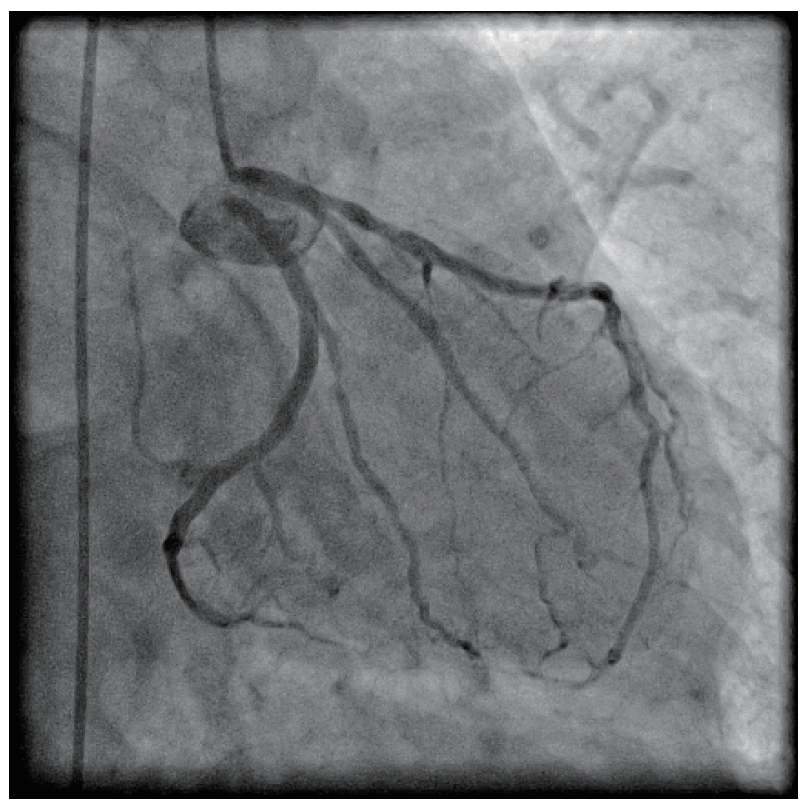

Figure 1. Coronary angiogram in right anterior oblique (RAO) caudal projection showing absent left main trunk with separate origin of left anterior descending artery (LAD) and left circumflex (LCX) from left sinus.
14.14\%. Ectopic origin of right coronary artery (RCA) from left sinus (Fig. 2) was seen in 12 patients, with an angiographic incidence of $0.37 \%$, and anomaly incidence of $12.12 \%$. Ectopic origin of RCA from ascending aorta (Fig. 3) was seen in four patients, with an angiographic incidence of $0.12 \%$ and anomaly incidence of $4.04 \%$. Ectopic origin of LCX from right sinus or RCA (Fig. 4) was noted in 13 patients, with an angiographic incidence of $0.40 \%$ and anomaly incidence of $13.13 \%$.

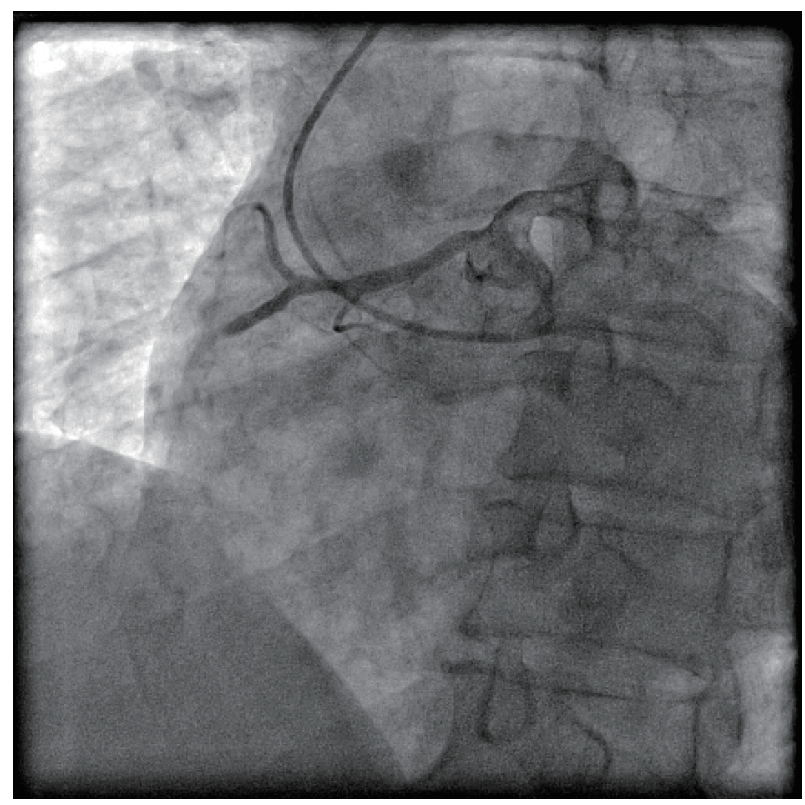

Figure 2. Coronary angiogram in left anterior oblique (LAO) projection showing origin of right coronary artery (RCA) from left sinus. RCA had critical stenosis in mid segment with slow flow. 


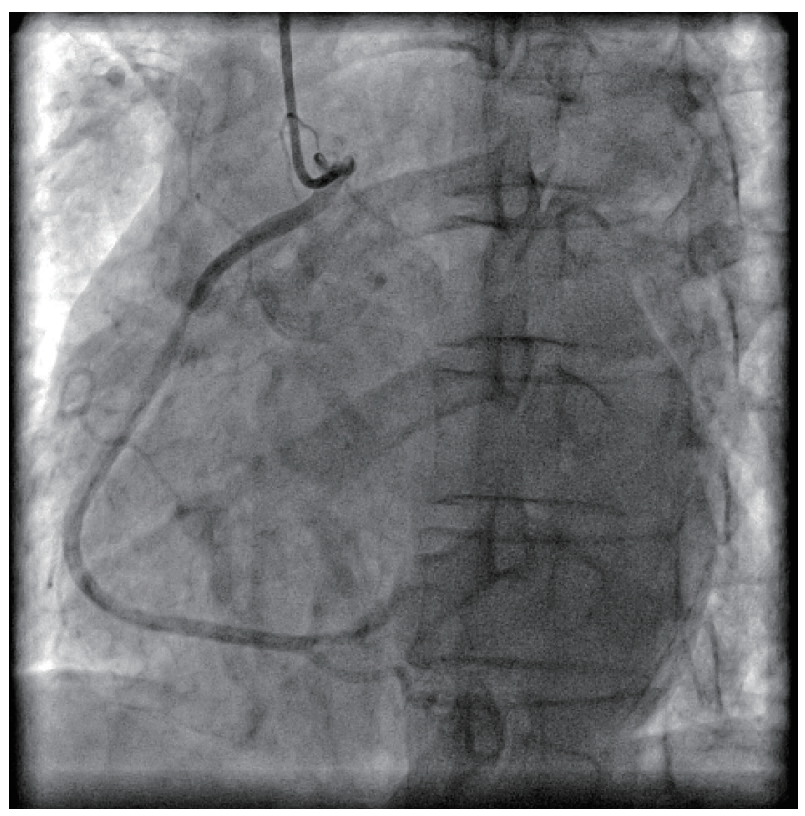

Figure 3. Coronary angiogram in left anterior oblique (LAO) projection showing origin of right coronary artery (RCA) from ascending aorta.

\section{Anomalies of intrinsic coronary arterial anatomy}

Split RCA (Fig. 5) was the most common coronary anomaly detected in the study, being seen in 27 patients, with an angiographic incidence of $0.84 \%$ and anomaly incidence of $27.27 \%$. Dual LAD (Fig. 6) was the second most common anomaly being seen in 22 cases with an angiographic incidence of $0.68 \%$ and anomaly incidence of $22.22 \%$. Superdominant LAD supplying the posterior descending artery (PDA) (Fig. 7) was seen

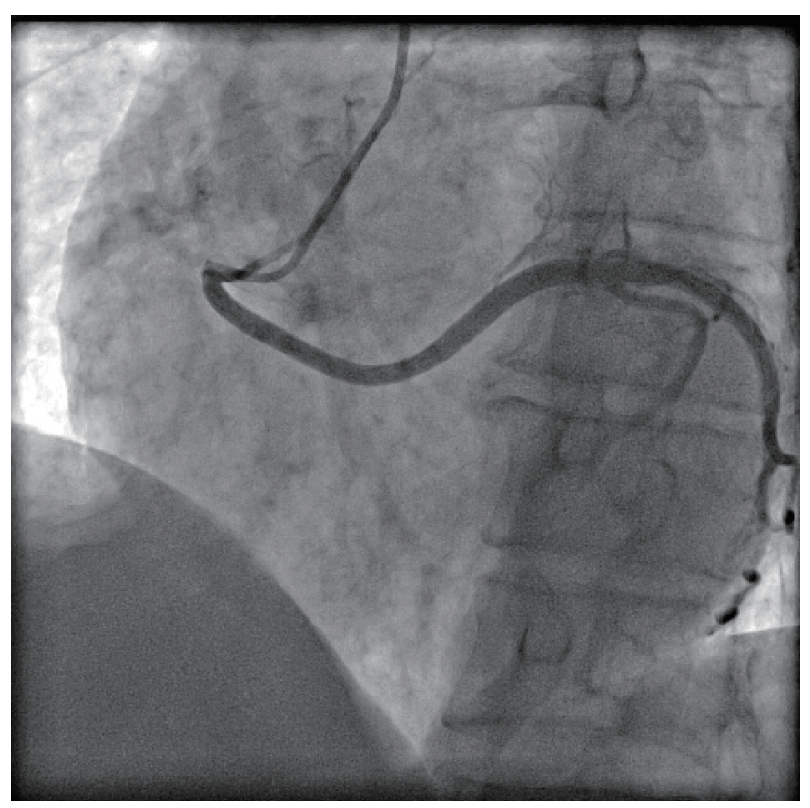

Figure 4. Coronary angiogram in left anterior oblique (LAO) projection showing ectopic origin of left circumflex artery (LCX) from right sinus.

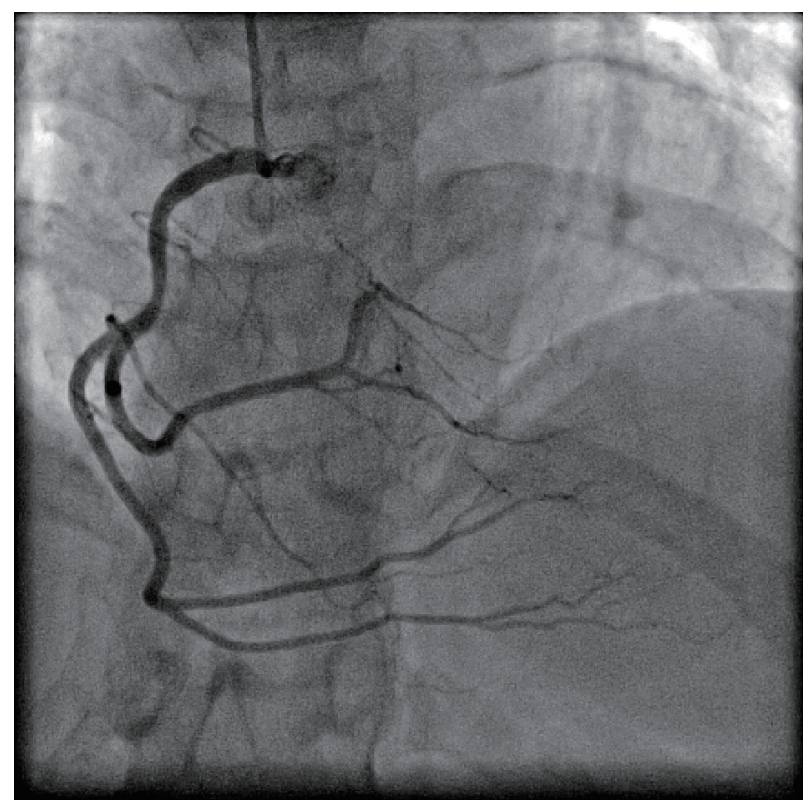

Figure 5. Coronary angiogram in anterior-posterior (AP) cranial projection showing split right coronary artery (RCA).

in one patient, with an angiographic incidence of $0.03 \%$ and anomaly incidence of $1.01 \%$.

\section{Anomalies of coronary termination}

Coronary artery fistulae were seen in six patients, with angiographic incidence of $0.18 \%$ and anomaly incidence of $6.06 \%$. Two patients had fistulae from proximal RCA to right atrium (Fig. 8). One patient had fistula draining from

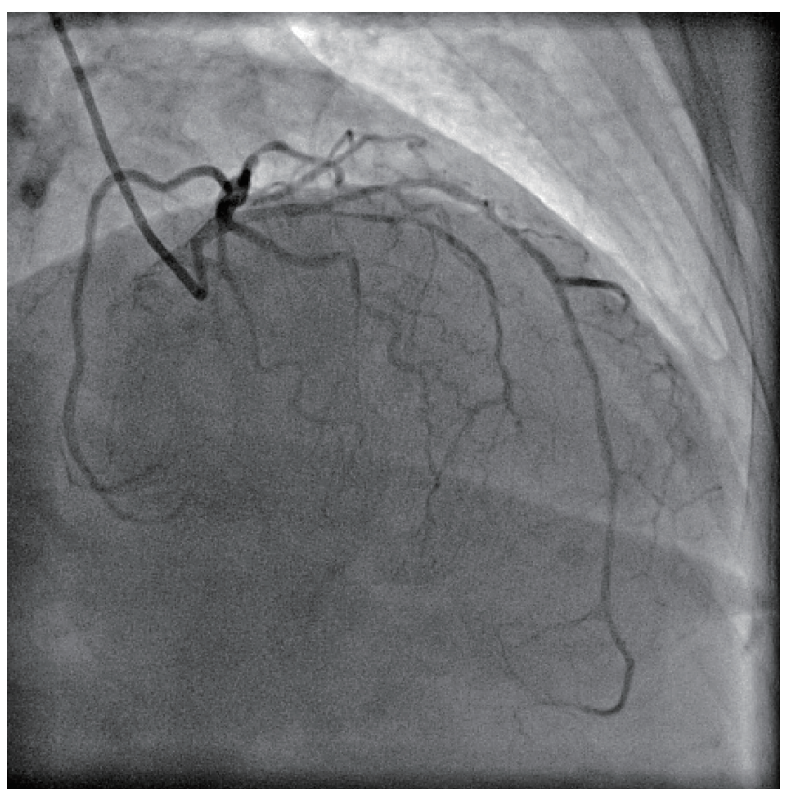

Figure 6. Coronary angiogram in right anterior oblique (RAO) cranial projection showing type I dual left anterior descending artery (LAD). 


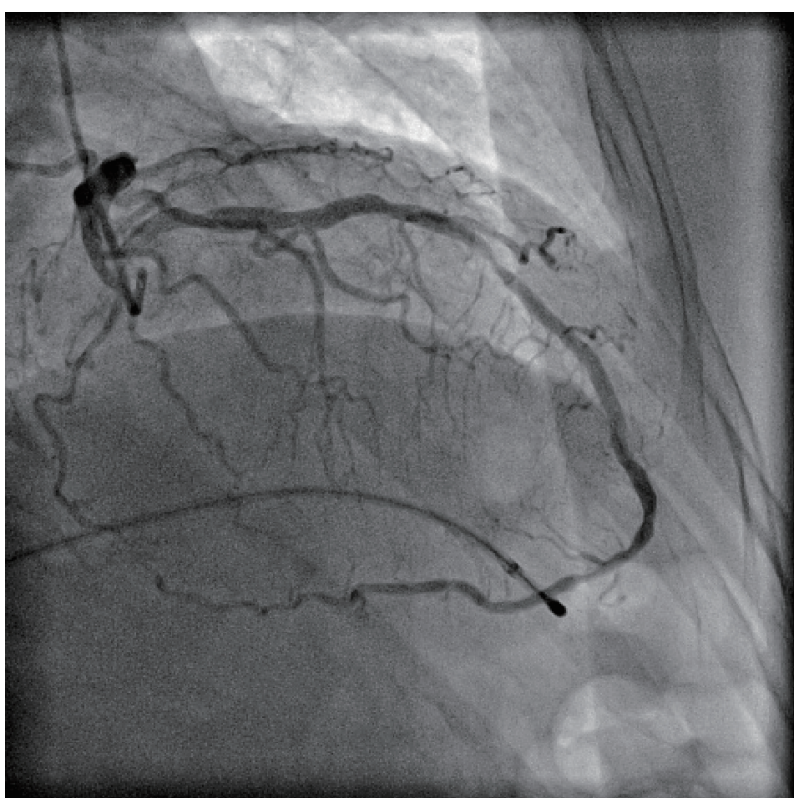

Figure 7. Coronary angiogram in right anterior oblique (RAO) cranial projection showing superdominant left anterior descending artery (LAD) continuing as posterior descending artery (PDA). Temporary pacing lead is seen in right ventricle (RV) apex as patient had third degree atrioventricular (AV) block.

proximal RCA into pulmonary artery branches, while another patient had fistula from proximal LAD into pulmonary artery. A unique case had bilateral fistulae with one fistula from proximal LAD into main pulmonary artery and another from proximal RCA into main pulmonary artery. One patient had fistula draining from proximal LCX into pulmonary artery branches. None of patients had symptoms attributable to coronary artery fistulae.

\section{CAD in anomalous coronary arteries}

Out of 99 patients with anomalous coronary arteries, 68 patients $(68.7 \%)$ were found be having significant $\mathrm{CAD}$; while 31 patients $(31.31 \%)$ had normal epicardial coronaries or insignificant $\mathrm{CAD}$. In patients with significant $\mathrm{CAD}$ triple vessel $\mathrm{CAD}$ was the most common pattern, being seen in 30 patients $(30.3 \%)$. Single vessel disease was seen in 20 patients $(20.2 \%)$, while double vessel disease was seen in 18 patients $(18.18 \%)$. One patient $(1.01 \%)$ had left main trunk involvement along with triple vessel disease. Fifty-three patients $(53.54 \%)$ had significant $\mathrm{CAD}$ in anomalous vessels, out of which 11 patients $(11.11 \%)$ had CAD restricted to anomalous vessels only. Fifteen patients $(15.15 \%)$ had significant CAD only in normal vessels. Out of total 382 vessels of 99 patients; 268 were normal vessels and 114 vessels were anomalous. Significant CAD was seen in 89 of $268(33.21 \%)$ normal vessels, whereas it was seen in 56 of $114(49.12 \%)$ of anomalous vessels. This difference was statistically significant $(\mathrm{P}=0.003)$, indicating $\mathrm{CAD}$ was more common in anomalous vessels than in normal vessels (Table 4).

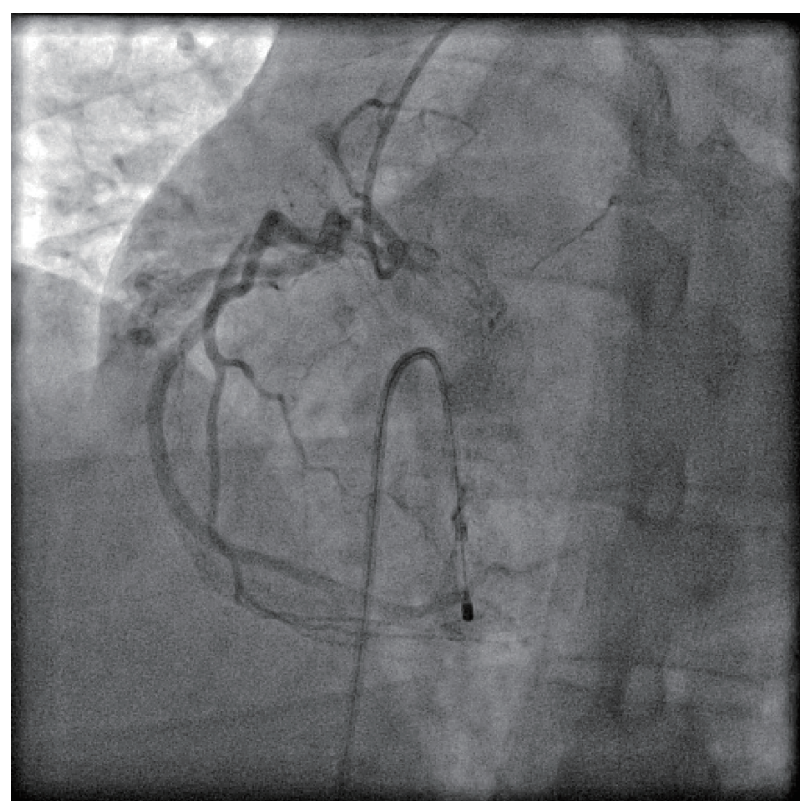

Figure 8. Coronary angiogram in left anterior-oblique (LAO) projection showing fistula from proximal right coronary artery (RCA), draining into right atrium $(\mathrm{RA})$.

\section{Discussion}

\section{Clinical characteristics of patients}

In our study, majority of patients with CAAs were males, which was similar to many previous studies $[2,3,7-9,24,27$ $29]$. This is probably due to more angiographies being performed in males. As we excluded the patients with congenital heart disease, the mean age in our study was $56.2 \pm 12.9$ years, and acute coronary syndromes were the most common indication for angiography in our study. Patients with CAAs had conventional CAD risk factors, with hypertension being the most common risk factor followed by diabetes mellitus. These findings are similar with many previous studies from India, probably reflecting the demographic profile of CAD in our country $[24,28,29]$.

\section{Incidence and patterns of coronary anomalies}

CAAs are a group of diverse disorders of coronary arterial anatomy which are rarely seen in general population. At present, there is no universally accepted definition and classification system of coronary anomalies. The classification system proposed by Angelini and coworkers is the most widely accepted classification system [22], which was followed in this study. Some authors do not consider coronary ectasia and myocardial bridging as coronary anomalies but rather consider these as variants of coronary anatomy [30-34]. Similarly, we also studied the incidence of CAAs excluding these variants.

The incidence of CAAs in the available literature (Table $5[2,3,7-13,23,24,27-29,35-38])$ is highly variable, and 
Table 4. Atherosclerotic Involvement of Coronary Arteries in Our Study

\begin{tabular}{lll} 
& Total number & Percentage (\%) \\
\hline Total patients with CAAs & 99 & 100 \\
Normal coronaries/insignificant CAD & 31 & 31.31 \\
Significant CAD & 68 & 68.69 \\
Single vessel disease & 20 & 20.20 \\
Double vessel disease & 18 & 18.18 \\
Triple vessel disease & 30 & 30.30 \\
LMCA involvement & 1 & 1.01 \\
Patients with CAD in anomalous vessels & 53 & 53.54 \\
Patients with CAD only in normal vessels & 15 & 15.15 \\
Patients with CAD only in anomalous vessels & 11 & 11.11 \\
\hline
\end{tabular}

CAAs: coronary artery anomalies; CAD: coronary artery disease; LMCA: left main coronary artery.

depends on several factors like characteristics of study population, definitions used and the type of imaging modality used. The incidence of CAAs in major angiographic studies has been reported to be $0.6 \%$ to $5.64 \%$ [2-13]. The incidence in the largest angiographic study by Yamanaka and Hobbs was $1.30 \%$, while it was $5.64 \%$ in the prospective study by Angelini et al using strict diagnostic criteria $[2,10]$. The incidence in our study was $3.06 \%$, being higher than most of the previ- ous studies but consistent with a few of these [10, 23, 28, 29]. Our results are closer to the prospectively conducted study by Angelini et al than most of the previous studies. This probably reflects the use of strict definitions and meticulous methodology in our study.

In our study, the anomalies of intrinsic coronary anatomy were the most common type, with split RCA being the single most common type of CAA with an incidence of $0.84 \%$. This

Table 5. Incidence and Patterns of Coronary Anomalies in Previous Studies

\begin{tabular}{|c|c|c|c|c|}
\hline Author/year of publication & Incidence $(\%)$ & Most common anomaly & $\begin{array}{l}\text { Imaging } \\
\text { modality }\end{array}$ & Country \\
\hline Yamanaka et al, 1990 [2] & $1.30(1,686$ of 126,595$)$ & Absent LM trunk with separate origin of LAD and LCX & CAG & USA \\
\hline Kaku et al, $1996[8]$ & $0.31(56$ of 17,731$)$ & Anomalous origin of RCA from LCS & CAG & Japan \\
\hline Kardos et al, 1997 [7] & $1.34(103$ of 7,694$)$ & Absent LM trunk with separate origin of LAD and LCX & CAG & $\begin{array}{l}\text { Central } \\
\text { Europe }\end{array}$ \\
\hline Garg et al, 2000 [9] & $0.95(39$ of 4,100$)$ & Anomalous origin of RCA from $\mathrm{LCS} / \mathrm{NCS}$ & CAG & India \\
\hline Yildiz et al, 2010 [3] & $0.90(112$ of 12,457$)$ & Absent LM trunk with separate origin of LAD and LCX & CAG & Turkey \\
\hline Erol et al, 2011 [11] & $1.96(53$ of 2,096$)$ & $\begin{array}{l}\text { Absent LM trunk with separate origin of LAD and LCX/ } \\
\text { origin of RCA from LCS }\end{array}$ & MDCT & Turkey \\
\hline Fujimoto et al, 2011 [12] & $1.52(89$ of 5,869$)$ & Anomalous origin of RCA from LCS & MDCT & Japan \\
\hline Sivri et al, 2012 [35] & $0.74(95$ of 12,814$)$ & Anomalous origin of LCX from RCS/RCA & CAG & Turkey \\
\hline Namgung et al, 2014 [37] & $1.16(103$ of 8,864$)$ & Anomalous origin of RCA from LCS & MDCT & Korea \\
\hline Tharwat et al, 2014 [23] & $2.7(115$ of 4,246$)$ & Anomalous origin of LCX from RCS/RCA & CAG & Egypt \\
\hline Altin et al, 2015 [38] & $1.4(78$ of 5,548$)$ & Absent LM trunk with separate origin of LAD and LCX & CAG & Turkey \\
\hline Sivakumar et al, 2017 [28] & $2.06(32$ of 1,547$)$ & Anomalous origin of RCA from LCS & CAG & India \\
\hline Somashekhara, 2017 [24] & $0.65(162$ of 25,023$)$ & Anomalous origin of RCA from LCS & CAG & India \\
\hline Nawale et al, 2018 [29] & $1.91(86$ of 4,481$)$ & Anomalous origin of RCA from LCS/NCS & CAG & India \\
\hline
\end{tabular}

LM: left main; LAD: left anterior descending artery; LCX: left circumflex artery; RCA: right coronary artery; RCS: right coronary sinus; LCS: left coronary sinus; NCS: non-coronary sinus; CAG: catheter coronary angiography; MDCT: multidetector computed tomography. 
result differs from most of the previous studies, but is consistent with the study by Angelini et al, who found split RCA to be the most common anomaly being present in $1.23 \%$ of the patients. This probably reflects the differences in definitions and methodologies being adopted by different investigators, leading to an underestimation of its true incidence.

Dual LAD was the second most common type of CAA in our study with an incidence of $0.68 \%$. Although our results differ from most of the previous studies; the incidence of dual LAD in our study was close to what was found by SpindolaFranco et al who found 23 cases of dual LAD after analyzing 2,140 coronary angiograms, with an incidence of $1 \%$ [39]. Many large angiographic studies related to CAAs have not reported on incidence of dual LAD. Two large studies which reported dual LAD are by Nawale et al and Sirasapalli et al $[29,40]$. Nawale et al found only a single case of dual LAD with an incidence of $0.02 \%$. Sirasapalli et al found five cases of dual LAD after analyzing 8,021 computed tomography (CT) coronary angiograms with an incidence of $0.59 \%$. We would like to attribute this to lack of uniform definitions or lack of awareness, resulting in under-recognition or under-reporting of the cases.

Absent left main trunk with separate origin of LAD and LCX from left sinus was the third most common anomaly detected in our study, with an incidence of $0.43 \%$. The incidence of this anomaly in our study was similar to many previous studies who reported this to be the most common CAA, such as Yamanaka and Hobbs $(0.41 \%)$, Erol and Seker $(0.43 \%)$ and Yildiz et al $(0.6 \%)[2,3,11]$.

Anomalous LCX originating from right sinus or RCA was seen in 13 cases in this study with an incidence of $0.4 \%$. Although few studies have reported this is to be the most common type of CAA (Table 5), the incidence rate of this anomaly in our results was similar to many studies like Yamanaka and Hobbs $(0.37 \%)$, Erol and Seker $(0.43 \%)$, Nawale et al $(0.33 \%)$ and Sivri et al $(0.36 \%)$ [2, 11, 29, 35].

Anomalous origin of RCA from left sinus is a potentially serious coronary anomaly. This anomaly can result in myocardial ischemia and life-threatening clinical manifestations like myocardial infarction, ventricular tachycardia, syncope and sudden death in the absence of significant atherosclerosis [2]. Although exact pathophysiological basis for this association is unclear, many authors have suggested different mechanisms. Yamanaka and Hobbs suggested that compression of proximal RCA by great arteries due to its inter-arterial course between aorta and pulmonary is responsible for myocardial ischemia at the time of exercise [2]. Taylor et al have proposed that acute angled takeoff of RCA from left sinus results in slitlike orifice, which can collapse in a valve-like manner leading to myocardial ischemia [41]. Kaku et al have suggested that proximal RCA situated between aorta and pulmonary artery is prone to compression or kinking phenomenon, resulting in intimal disruption and vasospasm; thus explaining the occurrence of myocardial ischemia in some patients at rest or low levels of exercise [42]. In our study anomalous origin of RCA from left sinus of Valsalva was present in 12 patients, with an angiographic incidence of $0.37 \%$. We did not encounter any life-threatening clinical manifestations in these patients except for a single case. Although this patient presented with isolated right ventricular infarction leading to heart failure, this was attributable to atherosclerotic occlusion of anomalous nondominant mid RCA; rather than due to compression of anomalously arising proximal RCA. Many studies have reported this anomaly to be the most common type of CAA (Table 5). Although, this was not the case in our study; the incidence rate in our study was similar to many of the previously published studies like Kaku et al $(0.32 \%)$, Garg et al (0.37\%), Fujimoto et al $(0.46 \%)$ and Namgung and $\operatorname{Kim}(0.46 \%)[8,9,12,37]$.

Anomalous origin of RCA from ascending aorta was seen in this study in four patients, with an incidence of $0.12 \%$. This was similar to that seen in study by Yamanaka and Hobbs $(0.15 \%)$, although lower than reported by Nawale et al $(0.33 \%)$ $[2,29]$.

In this study, we encountered a very rare case of superdominant LAD continuing beyond the cardiac apex as large PDA; with an incidence of $0.03 \%$. This extremely rare anomaly, also known as hyper-dominant LAD or type IV LAD; has only been sporadically reported in the literature in the form of case reports and has never been described in a large angiographic series [43-48]. In this anomaly, RCA is usually small and atretic, with a large PDA originating as continuation of distal LAD in posterior interventricular sulcus and supplying the inferior myocardial segments. This anomaly is usually considered benign, except in cases of atherosclerotic occlusion of LAD leading to extensive infarctions in anterior and inferior segments with its attendant complications like heart failure or cardiogenic shock.

Coronary artery fistulae are abnormal communications between one or more coronary arteries and the cardiac chambers or another blood vessel, such as vena cave, coronary sinus, pulmonary artery and bronchial veins. Incidence of coronary artery fistulae has been reported to range from $0.05 \%$ to $0.9 \%$ in several large selected series $[49,50]$. RCA is considered as the most common site of origin of these fistulae and rightsided cardiac chambers and vessels are the most common site of termination [51]. Most of the fistulae are small without any hemodynamic consequences, and are detected incidentally on echocardiography or cardiac catheterization. However in some cases, large fistulae lead to significant shunts and can cause pulmonary hypertension, heart failure, coronary steal phenomenon or rupture of the fistula. In our study fistulae were seen in six cases, with an incidence of $0.18 \%$. This incidence rate is similar to that seen in many studies, such as by Yamanaka and Hobbs $(0.17 \%)$, Tharwat et al $(0.21 \%)$, Namgung and Kim $(0.15 \%)[2,23,37]$. In our study RCA was the most common site of origin of coronary fistulae, and pulmonary artery was the most common site of termination. All of the fistulae in our study were small without causing any significant shunting and hence were considered benign.

\section{Atherosclerosis of anomalous coronaries}

The issue of atherosclerotic involvement of anomalous coronary arteries has generated considerable interest as well as controversy in the literature, with its incidence ranging from $1.7 \%$ to $72.2 \%$ in various studies $[8,9,23,29,52,53]$. In our study, atherosclerotic involvement of anomalous coronaries 
was noted in $53.54 \%$ of patients with CAAs. These results are similar to study by Nawale et al who found an incidence rate of $52.32 \%$ [29].

However, our results differ from Nawale et al in the aspect that we found atherosclerotic involvement to be more frequent in anomalous vessels, whereas their study showed rates of atherosclerosis to be similar in anomalous and normal coronaries. Our results are in agreement with Tharwat et al and Somashekhara who observed that CAAs are more frequently involved in atherosclerosis than the normal coronaries [23, 24]. In contrast, some studies have shown rates of atherosclerosis to be lower in anomalous coronaries than the normal coronaries [52, 54, 55].

\section{Limitations}

Being a single-center, retrospective study of patients undergoing catheter $\mathrm{CAG}$, our study had a referral bias and may not represent the general population. Our study population predominantly consisted of middle age adult population with acute coronary syndromes being the most common indication for $\mathrm{CAG}$, incidence of CAAs in general population may have been underestimated. In our study, the rates of atherosclerotic involvement of anomalous coronaries were compared with normal coronaries of the same patients and not with those of patients without anomalous coronaries. We believe that large prospective studies are needed to look into the relation between atherosclerosis and anomalous coronary arteries.

\section{Conclusions}

CAAs are a rare group of disorders of coronary anatomy which are mostly detected incidentally on CAG or autopsy. The incidence of CAAs in our study was slightly higher than many of the previous angiographic series. The patterns of coronary anomalies in our study were different from most of the previous studies, with split RCA being the most common anomaly in this study. Interestingly, our study had higher incidence of atherosclerotic involvement of anomalous vessels as compared to normal vessels; which is contrary to many of the previous studies.

\section{Acknowledgments}

We appreciate the help provided by Dr. Sumandeep Kaur during data analysis and manuscript preparation.

\section{Financial Disclosure}

None to declare.

\section{Conflict of Interest}

None to declare.

\section{Informed Consent}

Not applicable (retrospective study from hospital records).

\section{Author Contributions}

NSS: study design, data collection, analysis and manuscript preparation; GSW: data collection and manuscript preparation; AM: data collection and manuscript preparation; AK: data collection and manuscript preparation.

\section{References}

1. Basso C, Maron BJ, Corrado D, Thiene G. Clinical profile of congenital coronary artery anomalies with origin from the wrong aortic sinus leading to sudden death in young competitive athletes. J Am Coll Cardiol. 2000;35(6):14931501.

2. Yamanaka O, Hobbs RE. Coronary artery anomalies in 126,595 patients undergoing coronary arteriography. Cathet Cardiovasc Diagn. 1990;21(1):28-40.

3. Yildiz A, Okcun B, Peker T, Arslan C, Olcay A, Bulent Vatan M. Prevalence of coronary artery anomalies in 12,457 adult patients who underwent coronary angiography. Clin Cardiol. 2010;33(12):E60-64.

4. Leberthson RR, Dinsmore RE, Bharati S, Rubenstein JJ, Caulfield J, Wheeler EO, Harthorne JW, et al. Aberrant coronary artery origin from the aorta. Diagnosis and clinical significance. Circulation. 1974;50(4):774-779.

5. Alexander RW, Griffith GC. Anomalies of the coronary arteries and their clinical significance. Circulation. 1956;14(5):800-805.

6. Wilkins CE, Betancourt B, Mathur VS, Massumi A, De Castro CM, Garcia E, Hall RJ. Coronary artery anomalies: a review of more than 10,000 patients from the Clayton Cardiovascular Laboratories. Tex Heart Inst J. 1988;15(3):166-173.

7. Kardos A, Babai L, Rudas L, Gaal T, Horvath T, Talosi L, Toth K, et al. Epidemiology of congenital coronary artery anomalies: a coronary arteriography study on a central European population. Cathet Cardiovasc Diagn. 1997;42(3):270-275.

8. Kaku B, Shimizu M, Yoshio H, Ino H, Mizuno S, Kanaya $\mathrm{H}$, Ishise $\mathrm{S}$, et al. Clinical features of prognosis of Japanese patients with anomalous origin of the coronary artery. Jpn Circ J. 1996;60(10):731-741.

9. Garg N, Tewari S, Kapoor A, Gupta DK, Sinha N. Primary congenital anomalies of the coronary arteries: a coronary: arteriographic study. Int J Cardiol. 2000;74(1):39-46.

10. Angelini P, Velasco JA, Flamm S. Coronary anomalies: incidence, pathophysiology, and clinical relevance. Circulation. 2002;105(20):2449-2454.

11. Erol C, Seker M. Coronary artery anomalies: the prevalence of origination, course, and termination anomalies of coronary arteries detected by 64-detector computed tomography coronary angiography. J Comput Assist To- 
mogr. 2011;35(5):618-624.

12. Fujimoto S, Kondo T, Orihara T, Sugiyama J, Kondo M, Kodama T, Fukazawa H, et al. Prevalence of anomalous origin of coronary artery detected by multi-detector computed tomography at one center. J Cardiol. 2011;57(1):6976.

13. Yuksel S, Meric M, Soylu K, Gulel O, Zengin H, Demircan S, Yilmaz O, et al. The primary anomalies of coronary artery origin and course: A coronary angiographic analysis of 16,573 patients. Exp Clin Cardiol. 2013;18(2):121123.

14. Blake HA, Manion WC, Mattingly TW, Baroldi G. Coronary artery anomalies. Circulation. 1964;30:927-940.

15. Ogden JA. Congenital anomalies of the coronary arteries. Am J Cardiol. 1970;25(4):474-479.

16. Baltaxe HA, Wixson D. The incidence of congenital anomalies of the coronary arteries in the adult population. Radiology. 1977;122(1):47-52.

17. Roberts WC. Major anomalies of coronary arterial origin seen in adulthood. Am Heart J. 1986;111(5):941-963.

18. Dodge-Khatami A, Mavroudis C, Backer CL. Congenital Heart Surgery Nomenclature and Database Project: anomalies of the coronary arteries. Ann Thorac Surg. 2000;69(4 Suppl):S270-297.

19. Angelini P. Normal and anomalous coronary arteries: definitions and classification. Am Heart J. 1989;117(2):418434.

20. Shriki JE, Shinbane JS, Rashid MA, Hindoyan A, Withey JG, DeFrance A, Cunningham M, et al. Identifying, characterizing, and classifying congenital anomalies of the coronary arteries. Radiographics. 2012;32(2):453-468.

21. Angelini P. Coronary artery anomalies - current clinical issues: definitions, classification, incidence, clinical relevance, and treatment guidelines. Tex Heart Inst J. 2002;29(4):271-278.

22. Angelini P. Coronary artery anomalies: an entity in search of an identity. Circulation. 2007;115(10):1296-1305.

23. Tharwat M, El Ashtokhy MA, Mahfouz RA, Ibrahim AA. Angiographic study of anatomical variations of coronary arteries by using diagnostic catheter. Zagazig Univ Med J. 2015;20:826-833.

24. Somashekhara G. Clinical and angiographic profile of coronary artery anomalies in patients undergoing coronary angiography. J Cardiovasc Med Surg. 2017;3:167-174.

25. Serota H, Barth CW, 3rd, Seuc CA, Vandormael M, Aguirre F, Kern MJ. Rapid identification of the course of anomalous coronary arteries in adults: the "dot and eye" method. Am J Cardiol. 1990;65(13):891-898.

26. Cannon CP, Brindis RG, Chaitman BR, Cohen DJ, Cross JT, Jr., Drozda JP, Jr., Fesmire FM, et al. 2013 ACCF/ AHA key data elements and definitions for measuring the clinical management and outcomes of patients with acute coronary syndromes and coronary artery disease: a report of the American College of Cardiology Foundation/ American Heart Association Task Force on Clinical Data Standards (Writing Committee to Develop Acute Coronary Syndromes and Coronary Artery Disease Clinical Data Standards). Circulation. 2013;127(9):1052-1089.

27. Sohrabi B, Habibzadeh A, Abbasov E. The incidence and pattern of coronary artery anomalies in the north-west of iran: a coronary arteriographic study. Korean Circ J. 2012;42(11):753-760.

28. Sivakumar GS, Selvarani G, Kumar SS, Ramesh R, Hemanath TR, Manikandan D. Incidence of coronary artery anomalies among patients undergoing coronary angiography and its relevance to appropriate choice of coronary catheter selection-a tertiary care center study. Int J Sci Study. 2017;5:228-231.

29. Nawale JM, Chaurasia AS, Nalawade DD, Choudalwar P, Borikar N, Tiwari D. Study of clinical profille, incidence, pattern, and atherosclerotic involvement of congenital coronary artery anomalies in adults undergoing coronary angiography: A study from a tertiary care institute in western part of India. Heart India. 2018;6:133-140.

30. Hartnell GG, Parnell BM, Pridie RB. Coronary artery ectasia. Its prevalence and clinical significance in 4993 patients. Br Heart J. 1985;54(4):392-395.

31. Ete T, Kavi G, Mishra A, Jha PK, Malviya A, Megeji RD. Coronary artery ectasia, an enigma in cardiology: A case report with review of literature. Heart India. 2016;4:149152.

32. Mavrogeni S. Coronary artery ectasia: from diagnosis to treatment. Hellenic J Cardiol. 2010;51(2):158-163.

33. Lazoura O, Kanavou T, Vassiou K, Gkiokas S, Fezoulidis IV. Myocardial bridging evaluated with 128-multi detector computed tomography coronary angiography. Surg Radiol Anat. 2010;32(1):45-50.

34. Konen E, Goitein O, Di Segni E. Myocardial bridging, a common anatomical variant rather than a congenital anomaly. Semin Ultrasound CT MR. 2008;29(3):195203.

35. Sivri N, Aktoz M, Yalta K, Ozcelik F, Altun A. A retrospective study of angiographically determined anomalous coronary arteries in 12,844 subjects in Thrace region of Turkey. Hippokratia. 2012; 16(3):246-249.

36. Xu H, Zhu Y, Zhu X, Tang L, Xu Y. Anomalous coronary arteries: depiction at dual-source computed tomographic coronary angiography. J Thorac Cardiovasc Surg. 2012;143(6):1286-1291.

37. Namgung J, Kim JA. The prevalence of coronary anomalies in a single center of Korea: origination, course, and termination anomalies of aberrant coronary arteries detected by ECG-gated cardiac MDCT. BMC Cardiovasc Disord. 2014;14:48.

38. Altin C, Kanyilmaz S, Koc S, Gursoy YC, Bal U, Aydinalp A, Yildirir A, et al. Coronary anatomy, anatomic variations and anomalies: a retrospective coronary angiography study. Singapore Med J. 2015;56(6):339-345.

39. Spindola-Franco H, Grose R, Solomon N. Dual left anterior descending coronary artery: angiographic description of important variants and surgical implications. Am Heart J. 1983;105(3):445-455.

40. Sirasapalli CN, Christopher J, Ravilla V. Prevalence and spectrum of coronary artery anomalies in 8021 patients: A single center study in South India. Indian Heart J. 2018;70(6):852-856.

41. Taylor AJ, Rogan KM, Virmani R. Sudden cardiac death associated with isolated congenital coronary artery anom- 
alies. J Am Coll Cardiol. 1992;20(3):640-647.

42. Kaku B, Kanaya H, Ikeda M, Uno Y, Fujita S, Kato F, Oka T. Acute inferior myocardial infarction and coronary spasm in a patient with an anomalous origin of the right coronary artery from the left sinus of valsalva. Jpn Circ J. 2000;64(8):641-643.

43. Singh SP, Soto B, Nath H. Anomalous origin of posterior descending artery from left anterior descending artery with unusual intraseptal course. J Thorac Imaging. 1994;9(4):255-257.

44. Javangula K, Kaul P. Hyperdominant left anterior descending artery continuing across left ventricular apex as posterior descending artery coexistent with aortic stenosis. J Cardiothorac Surg. 2007;2:42.

45. Ramesh Babu CS, Khare S, Asthana AK, Saxena S, Gupta OP. Posterior descending artery arising as a continuation of hyperdominant left anterior descending artery. Int J Anatomy Radiol Surg. 2015;4:16-19.

46. Udupa A, Goyal BK, Pagad S. Hyperdominant left anterior descending artery (LAD): A rare coronary anomaly. Indian Heart J. 2016;68(Suppl 2):S151-S152.

47. Clark VL, Brymer JF, Lakier JB. Posterior descending artery origin from the left anterior descending: an unusual coronary artery variant. Cathet Cardiovasc Diagn. 1985;11(2):167-171.

48. Patra S, Srinivas BC, Agrawal N, Manjunath CN. Super dominant left anterior descending artery with the origin of both posterior descending artery and posterior left ventricular artery from the septal branch. BMJ Case Rep. 2013;2013:1-3.

49. van den Brand M, Pieterman H, Suryapranata H, Bogers AJ. Closure of a coronary fistula with a transcatheter implantable coil. Cathet Cardiovasc Diagn. 1992;25(3):223226.

50. Lim JJ, Jung JI, Lee BY, Lee HG. Prevalence and types of coronary artery fistulas detected with coronary CT angiography. AJR Am J Roentgenol. 2014;203(3):W237-243.

51. Challoumas D, Pericleous A, Dimitrakaki IA, Danelatos C, Dimitrakakis G. Coronary arteriovenous fistulae: a review. Int J Angiol. 2014;23(1):1-10.

52. Eid AH, Itani Z, Al-Tannir M, Sayegh S, Samaha A. Primary congenital anomalies of the coronary arteries and relation to atherosclerosis: an angiographic study in Lebanon. J Cardiothorac Surg. 2009;4:58.

53. Harikrishnan S, Jacob SP, Tharakan J, Titus T, Kumar VK, Bhat A, Sivasankaran S, et al. Congenital coronary anomalies of origin and distribution in adults: a coronary arteriographic study. Indian Heart J. 2002;54(3):271-275.

54. Topaz O, DeMarchena EJ, Perin E, Sommer LS, Mallon SM, Chahine RA. Anomalous coronary arteries: angiographic findings in 80 patients. Int J Cardiol. 1992;34(2):129-138.

55. Zhang F, Ge JB, Qian JY, Fan B, Wang QB, Chen HZ. [Frequency of the anomalous coronary origin in the Chinese population with coronary artery stenosis]. Zhonghua Nei Ke Za Zhi. 2005;44(5):347-349. 